\title{
Economic security of the southern Caucasus: opportunities and challenges
}

ABSTRACT. The southern Caucasus is one of the most interesting and, at the same time, vulnerable regions of the world. Different confessions, national traditions, lifestyles, human philosophies, economic approaches and a lot of other fundamental values are united here in a single contradictory node. At the same time, strategic interests of the USA, the EU, Russia, China, Turkey and Iran contradictorily intersect here. After the collapse of the USSR and a huge economic crisis, the southern Caucasus states manifested picturesque and intense social and economic development: within several years all three southern Caucasus countries have left the group of low-income countries and joined the upper-middle income states. The region has some of the most developed infrastructure in the world: the total length of pipelines in the region is $9,873 \mathrm{~km}$; the total length of roads equals $53.315 \mathrm{~km}$; and that of the railway network equals 4,556 km. More than 8.8 million people passed through the three Azerbaijani, three Georgian and one Armenian international airports in 2017, and 11.7 million people visited the three states (including 7.6 million visitors to Georgia). For their accommodation the regional hotel industry possesses 62,111 beds, and this number will increase to 75,860 in 2021. Georgia has close bilateral commercial relations with both Armenia and Azerbaijan but no partnership of Armenia, neither with Azerbaijan nor with Turkey, is possible. Exports of goods and commodities from the three southern Caucasus states complement each other and a synergetic approach to foreign trade may significantly improve the exports' added value. Further development and economic security of the region would greatly depend on both the increase of hydrocarbon exports with involvement of their resources from other countries and the implementation of modern trade technologies. From this point of view the foundation of the Caucasus Commodity Exchange and affiliated bank institutions seems to be of crucial importance. Application of futures and options trade and hedging would at least double the capitalization of companies and the liquidity of the regional market. Without such innovations the economy of the region will begin to slow down. In so far as far as the stability in the region has a huge impact on international security, the international community will be deeply be implicated in these matters.

Nanotechnology Perceptions 15 (2019) 21-47

doi: 10.4024/N01TV19A.ntp.15.01 